\title{
Effect of Heater Configurations on Transient Heat Transfer for Various Gases Flowing over a Twisted Heater*
}

\author{
Makoto SHIBAHARA $^{* *}$, Qiusheng LIU $^{* *}$ and Katsuya FUKUDA ${ }^{* *}$ \\ ${ }^{* *}$ Graduate School of Maritime Sciences, Kobe University, \\ 5-1-1, Fukaeminami, Higashinada, Kobe 658-0022, JAPAN \\ E-mail: qsliu@maritime.kobe-u.ac.jp
}

\begin{abstract}
Forced convection transient heat transfer coefficients were measured for helium gas and carbon dioxide gas flowing over a twisted heater due to exponentially increasing heat input. The twisted platinum ribbon with a thickness of $0.1 \mathrm{~mm}$ was used as test heater and heated by electric current. The heat generation rate was exponentially increased with a function of $\mathrm{Q}_{0} \exp (\mathrm{t} / \tau)$. The gas flow velocities ranged from 1 to $10 \mathrm{~m} / \mathrm{s}$, the gas temperatures ranged from 313 to $353 \mathrm{~K}$, and the periods of heat generation rate ranged from $46 \mathrm{~ms}$ to $17 \mathrm{~s}$. The surface temperature difference and heat flux increase exponentially as the heat generation rate increases exponentially. Transient heat transfer coefficients increase with increasing gas flow velocity. The heater configuration of twisted heater in this study shows a large effect on the heat transfer coefficient. Empirical correlations for quasi-steady-state heat transfer were obtained based on the experimental data.
\end{abstract}

Key words: Transient Heat Transfer, Forced Convection, Enhancement, Twisted Heater

\section{Introduction}

The knowledge of steady and transient forced convection heat transfer for various gases is important in many industrial fields. The behavior of heat transfer devices such as heat exchangers in industrial plants during transient temperature changes caused undesirable effects such as reduced thermal performance and thermal stress with eventual mechanical failure. In addition, it is also important for safety assessment of the transient heat transfer process due to a reactivity insertion event in nuclear power plants such as Very High Temperature Reactor (VHTR), which is one of generation IV ${ }^{(1)}$ reactors. The VHTR is a new type reactor in the evolutional development of High Temperature Gas-cooled Reactor (HTGR) which use helium gas as primary coolant for graphite matrix, coated fuel particles. According to the control rod withdrawal test of High Temperature Engineering Test Reactor (HTTR) reported by Takamatsu et al. ${ }^{(2)}$, when the reactivity insertion test was carried out, the rapid increase of rector power during withdrawal of the control rod is restrained by only the negative reactivity feed back effect without operation of the reactor power control system, and the increase of the temperature at the transient process of the reactor is slow. However, although the effect of negative reactivity feed back due to increase of the fuel temperature is expected at that case, it takes about 10s until the negative reactivity feed back becomes to appear. Since the fuel temperature during the excess reactivity transient 
process is rapidly higher than that at steady-state condition (normal operation), it is necessary to investigate the detailed knowledge of transient heat transfer process. In this paper, we studied on the transient heat transfer process and investigated the effect of heater configurations on transient heat transfer as a fundamental research on heat transfer enhancement.

The transient heat transfer has not been solved though many analytical solutions and experiments were reported concerning the steady state heat transfer. Concerning the problem of transient heat transfer with exponentially increasing heat generation rate $\left(\dot{\mathrm{Q}}=\mathrm{Q}_{0} \exp (\mathrm{t} / \tau)\right.$, where, $\dot{\mathrm{Q}}$ is heat generation rate, $\mathrm{Q}_{0}$ is initial heat generation rate, $\mathrm{t}$ is time, and $\tau$ is period of heat generation rate (a time needed for $\dot{Q}$ to increase e-fold.)), there are only a few analytical and experimental works as far as the authors know. In 1960, Siegel ${ }^{(3)}$ analyzed the transient heat transfer for laminar flows in parallel plate and tube for step changes in wall temperature. Soliman et al. ${ }^{(4)}$ analytically obtained a temperature change in plate by taking into account the turbulent boundary around the plate. However, the solution of heat transfer coefficient for water is $50 \%$ higher than their experimental data. Kataoka et al. ${ }^{(5)}$ conducted the transient experiment of water which flows in parallel to a cylinder, and obtained an empirical correlation for the ratios between the transient heat transfer coefficient and steady state one in term of one nondimensional parameter composed of period, velocity, and heater length. Liu and Fukuda ${ }^{(6),(7)}$ obtained the experimental data and correlation for both parallel flow and cross-flow of helium gas over a horizontal cylinder. However, the experimental data were limited to a cylinder for the parallel flow, and limited to a low-Reynolds number region for the cross flow. Then Liu et al. ${ }^{(8),(9),(10)}$, and Shibahara et al. ${ }^{(11)}$ obtained the experimental data and correlation for horizontal cylinders and plates under the wide experimental condition to investigate the transient heat transfer phenomena for helium gas and carbon dioxide gas. However, there was no detailed knowledge of the effect of heater configuration on transient heat transfer for various gases.

In this research, transient forced convection heat transfer due to exponentially increasing heat input for helium gas and carbon dioxide gas flowing over a twisted heater was experimentally studied to understand transient heat transfer characteristics at different heater configurations as the fundamental knowledge of heat transfer enhancement on the heat transfer devices. The purposes are: (1), to obtain experimental data at various periods, gas flow velocities, and gas temperatures for helium gas and carbon dioxide gas, respectively; (2), to clarify the effect of heater configuration on steady-state and transient heat transfer; (3), to compare the heat transfer coefficients with those reported in authors' previous papers ${ }^{(9),(10),(11)}$.

\section{Nomenclature}

$\mathrm{c}_{\mathrm{h}} \quad$ specific heat of test heater, $\mathrm{J} /(\mathrm{kgK})$

$\mathrm{h}$ heat transfer coefficient, $(=\mathrm{q} / \Delta \mathrm{T}), \mathrm{W} / \mathrm{m}^{2} \mathrm{~K}$

$\mathrm{L}$ effective length of heater, $\mathrm{m}$

$\mathrm{Nu}$ Nusselt number, $\mathrm{hL} / \lambda$

Pr Prandtl number

$\dot{\mathrm{Q}}$ heat generation rate per unit volume, $\mathrm{W} / \mathrm{m}^{3}$

$\mathrm{Q}_{0} \quad$ initial heat generation rate per unit volume, $\mathrm{W} / \mathrm{m}^{3}$

q heat flux, $\mathrm{W} / \mathrm{m}^{2}$

Re Reynolds number, UL/v

$\mathrm{T}$ temperature, $\mathrm{K}$

$\Delta \mathrm{T}$ surface temperature difference $\left(=\mathrm{T}_{\mathrm{s}}-\mathrm{T}_{\mathrm{b}}\right), \mathrm{K}$

$\mathrm{t}$ time, $\mathrm{s}$

$\mathrm{U}$ gas flow velocity, $\mathrm{m} / \mathrm{s}$ 
$\delta \quad$ heater thickness, $\mathrm{m}$

$\rho_{\mathrm{h}} \quad$ density of test heater, $\mathrm{kg} / \mathrm{m}^{3}$

$\lambda$ thermal conductivity, $\mathrm{W} / \mathrm{mK}$

$v \quad$ kinematic viscosity, $\mathrm{m}^{2} / \mathrm{s}$

$\tau$ period of heat generation rate, $\mathrm{s}$

$\tau *$ dimensionless period, $(=\tau \mathrm{U} / \mathrm{L})$

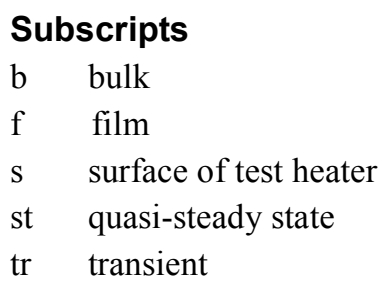

\section{Experimental Apparatus and Method}

\subsection{Schematic Diagram of Experimental Apparatus}

Experimental apparatus was reported in previous papers ${ }^{(6),}{ }^{(9)}$. Figure 1 shows a schematic diagram of the experimental apparatus. The experimental apparatus is composed of gas compressor (2), flow meter (5), test section (6), surge tank (3), (8), cooler (7), heat input control system, and data measurement and processing system. The vacuum pump was used to degas the loop and test section. The gas was circulated by compressor, and the fluctuations of gas flowing and pressure due to compressor were removed with the surge tanks. Moreover, the gas temperature inside the loop was heated to the desired temperature level by a pre-heater, and cooled by a cooler before the gas flows into the compressor. A gas flow velocity in the test section was measured with the turbine meter, and the pressure was measured with the pressure transducer. The temperature of the turbine meter exit and the temperature near test section heater were measured by K-type thermocouples with a precision of $\pm 1 \mathrm{~K}$. Helium gas and carbon dioxide gas with a high purity of $99.9 \%$ were used as the test fluid.

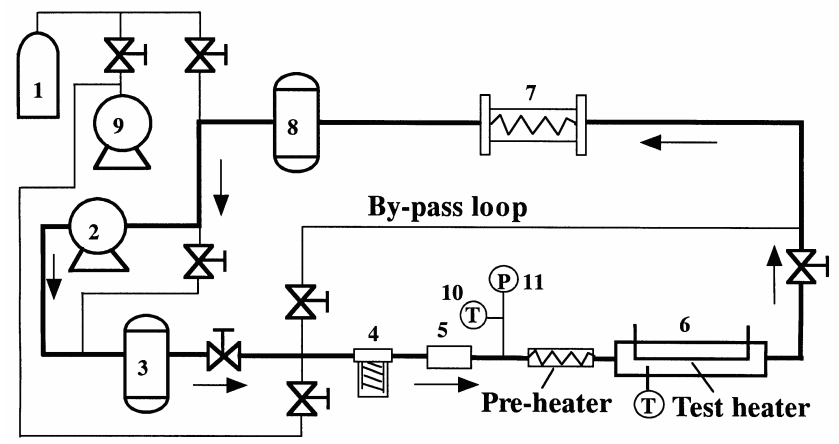

1.Gas cylinder 2.Compressor 3.Delivery surge tank 4.Filter 5.Turbine flow meter 6.Test section 7.Cooler 8.Suction surge tank 9.Vacuum pump 10.Thermocouple 11.Pressure indicator

Fig.1 Schematic diagram of experimental apparatus.

\subsection{Test Section and Test Heater}

Figure 2 shows a vertical cross-sectional view of the test section. The twisted heater was mounted horizontally along the center part of the circular test channel, which is made of the stainless steel of $82 \mathrm{~mm}$ in width, $100 \mathrm{~mm}$ in height and $300 \mathrm{~mm}$ in length. The inside diameter is $20 \mathrm{~mm}$. Platinum plate (ribbon) with a thickness of $0.1 \mathrm{~mm}$, and a width of $4.0 \mathrm{~mm}$ was used as the test heater. It was twisted at the center of the heater with an angle 
of $90^{\circ}$ with respect to the upper part of heater, as shown in Fig.2. The test heater was 50 $\mathrm{mm}$ in length; both ends of it were connected to two copper plates with the thickness of $0.7 \mathrm{~mm}$, then connected to two copper electrodes. Two fine platinum wires $(0.05 \mathrm{~mm}$-dia.) were spot welded to the central parts of the plate as potential conductors. The effective length of the test heater between the potential taps, on which transient heat transfer was measured was $40 \mathrm{~mm}$. In order to measure the bulk gas temperature, the thermocouples were inserted into the circular test channel from the opposite side of the mounted heater.

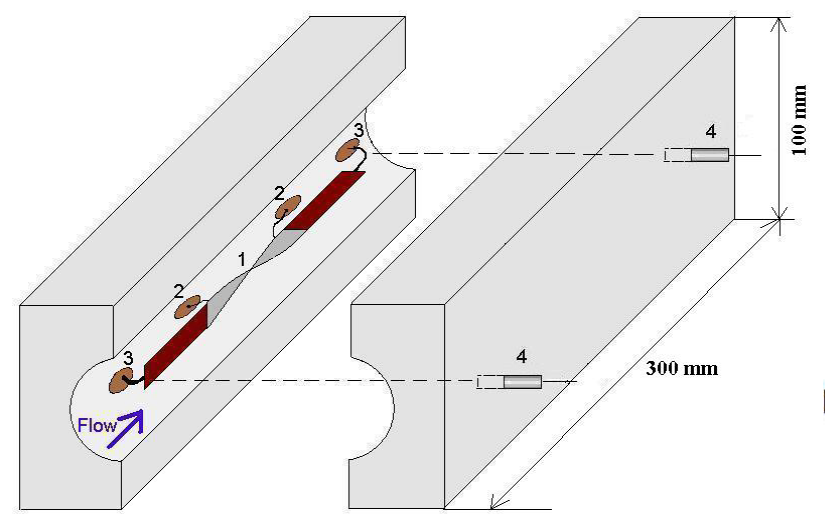

A-A'

Vertical cross-sectional view

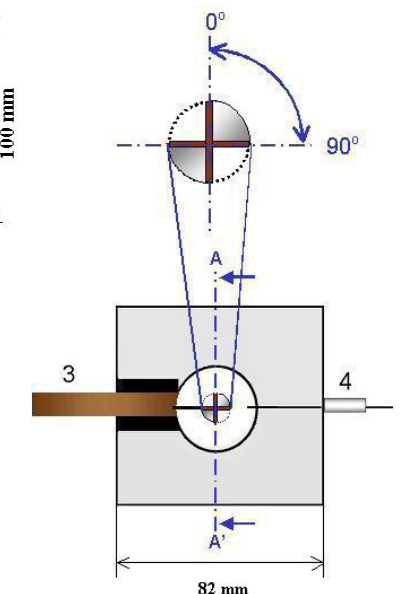

\section{Test heater 2.Potential conductor 3.Current conductor 4.Thermocouple \\ 1.Test heater 2.Potential conductor 3.Current conductor 4.Thermocouple}

Fig.2 Test section

\subsection{Experimental Method and Procedure}

The platinum test heater was heated by direct current from a power source. The heat generation rates of the heater were controlled and measured by a heat input control system ${ }^{(6)}$. The average temperature of the test heater was measured by resistance thermometry using a double bridge circuit including the test heater as a branch ${ }^{(6)}$. The test heater was annealed and its electrical resistance versus temperature relation was calibrated in water, and washed with a trichloroethylene liquid before using it in the experiment. The average temperature of the test heater was calculated from the previously calibrated resistance-temperature relation. In data processing, a personal computer was used. The unbalanced voltage of the double-bridge circuit including the heater and the voltage differences between the potential taps of the heater and across the standard resistance were fed to the personal computer through an analog-to-digital (A/D) converter $^{(6)}$.

The heat flux on the surface of test heater, $\mathrm{q}\left(\mathrm{W} / \mathrm{m}^{2}\right)$, is calculated by the following equation.

$$
\mathrm{q}=\frac{\delta}{2}\left(\dot{\mathrm{Q}}-\rho_{\mathrm{h}} \mathrm{c}_{\mathrm{h}} \frac{\mathrm{dT}}{\mathrm{dt}}\right)
$$

where, $\rho_{\mathrm{h}}, \mathrm{c}_{\mathrm{h}}$, and $\delta$ are the density, specific heat, and thickness of the test heater, respectively. $\dot{Q}\left(\mathrm{~W} / \mathrm{m}^{3}\right)$ is the internal heat generation rate, $\mathrm{T}_{\mathrm{a}}(\mathrm{K})$ is the average temperature of the test heater.

Using the measured average temperature of the test heater, the test heater surface temperature was calculated from heat conduction equation of the test heater by assuming the surface temperature around the test heater to be uniform.

When the experimental data were processed, the physical properties of the fluid were 
calculated based on the following film temperature, which was used as a reference temperature:

$$
\mathrm{T}_{\mathrm{f}}=\frac{\mathrm{T}_{\mathrm{s}}+\mathrm{T}_{\mathrm{b}}}{2}
$$

where, $T_{s}$ and $T_{b}$ are the test heater surface temperature, and the bulk gas temperature, respectively.

The uncertainties of the measurement of the heat generation rate, the heat flux of the test heater, and the heater surface temperature are estimated to be $\pm 1 \%, \pm 2 \%$, and \pm 1 $\mathrm{K}$, respectively. And the uncertainty for the obtained heat transfer coefficients is estimated to be $\pm 2.5 \%$.

The experiments were carried out according to the following procedure. The test loop was first filled with the helium gas or carbon dioxide gas after degassing by a vacuum pump. The working fluid was circulated by a compressor. A flow velocity was controlled in stages from maximum flow velocity to minimum one. The regulation of a flow velocity was carried out by using the by-pass valves of the test section and the by-pass valve of the compressor. After the pressure was confirmed to be stable at each flow velocity in the loop, the electric current was supplied to the test heater, and the heat generation rate was raised exponentially, then the test heater surface temperature and the heat flux accompanying the passage of the time were measured.

\section{Experimental Results and Discussion}

\subsection{Experimental Conditions}

The transient heat transfer experimental data for helium gas and carbon dioxide gas were measured for the periods of heat generation rate ranged from $46 \mathrm{~ms}$ to $17 \mathrm{~s}$ and temperatures ranged from $313 \mathrm{~K}$ to $353 \mathrm{~K}$ under the absolute pressure of $500 \mathrm{kPa}$. The flow velocities ranged from 1 to $10 \mathrm{~m} / \mathrm{s}$, and the corresponding Reynolds numbers ranged from $3.62 \times 10^{3}$ to $3.78 \times 10^{4}$. Reynolds number was defined as $\operatorname{Re}_{\mathrm{f}}=\mathrm{UL} / v_{\mathrm{f}}$. Where, $\mathrm{U}$ is the flow velocity, $\mathrm{L}$ is the effective length of the test heater, and $v_{\mathrm{f}}$ is the kinematic viscosity of the gas, respectively. The heat generation rate was raised with exponential function, $\dot{\mathrm{Q}}=\mathrm{Q}_{0} \exp (\mathrm{t} / \tau)$. Where, $\dot{\mathrm{Q}}$ is heat generation rate, $\mathrm{W} / \mathrm{m}^{3}, \mathrm{Q}_{0}$ is initial heat generation rate, $\mathrm{W} / \mathrm{m}^{3}, \mathrm{t}$ is time, $\mathrm{s}$, and $\tau$ is period of heat generation rate, $\mathrm{s}$, respectively. A smaller or shorter period means a higher increasing rate of heat generation.

\subsection{Experimental Data of Heat Generation Rate, Surface Temperature Difference, and Heat Flux}

Figure 3 shows typical experimental data of the time-dependence of heat generation rate, $\dot{\mathrm{Q}}$, surface temperature difference, $\Delta \mathrm{T}$, and heat flux, $\mathrm{q}$, at the helium gas temperature of $313 \mathrm{~K}$ and the heat generation rate increasing periods of $1.68 \mathrm{~s}, 708 \mathrm{~ms}, 429 \mathrm{~ms}$, and 175 $\mathrm{ms}$, respectively. The gas flow velocity is $10 \mathrm{~m} / \mathrm{s}\left(\mathrm{Re}_{\mathrm{f}}=9.23 \times 10^{3}\right)$. The symbols of square show the increasing speed of $\Delta \mathrm{T}$ at $\mathrm{t} / \tau=4$. As shown in this figure, heat generation rate, heat flux and temperature difference increase rapidly as the period is shorter. And also, the increasing speed of $\Delta \mathrm{T}$ increases greatly for shorter periods. It is understood that the surface temperature difference and heat flux increase exponentially as the heat generation rate increases with exponential function.

\subsection{Transient Heat Transfer Coefficient at Various Periods of Heat Generation Rate}

Heat transfer coefficient can be obtained from the measured heat flux and surface temperature difference $(\mathrm{h}=\mathrm{q} / \Delta \mathrm{T})$. Figure 4 shows the heat transfer coefficients at various periods of heat generation rate at the gas temperature of $313 \mathrm{~K}$ for helium gas. The heat 
transfer coefficient, $h$, becomes to approach asymptotic value at every velocity when $\tau$ is longer than about $1 \mathrm{~s}$. The heat transfer process in this region transmits heat as well as usual convective heat transfer through the thermal boundary layer influenced by the flow of helium gas. It is called the quasi-steady-state heat transfer here. On the other hand, when the period, $\tau$, is shorter than about $1 \mathrm{~s}$, h increases as $\tau$ shortens. This shows that the heat transfer process is in the unsteady state. In the region of $\tau$ shorter than $200 \mathrm{~ms}$, the conductive heat transfer near the heater comes to govern the heat transfer process, and the heat transfer coefficient increases greatly with shorter period in this region. It was clarified that the heat transfer phenomenon was divided into a quasi-steady-state heat transfer and a transient heat transfer on the boundary of around $1 \mathrm{~s}$. The coefficient of heat transfer increases with the flow velocity as shown in the Fig.4.
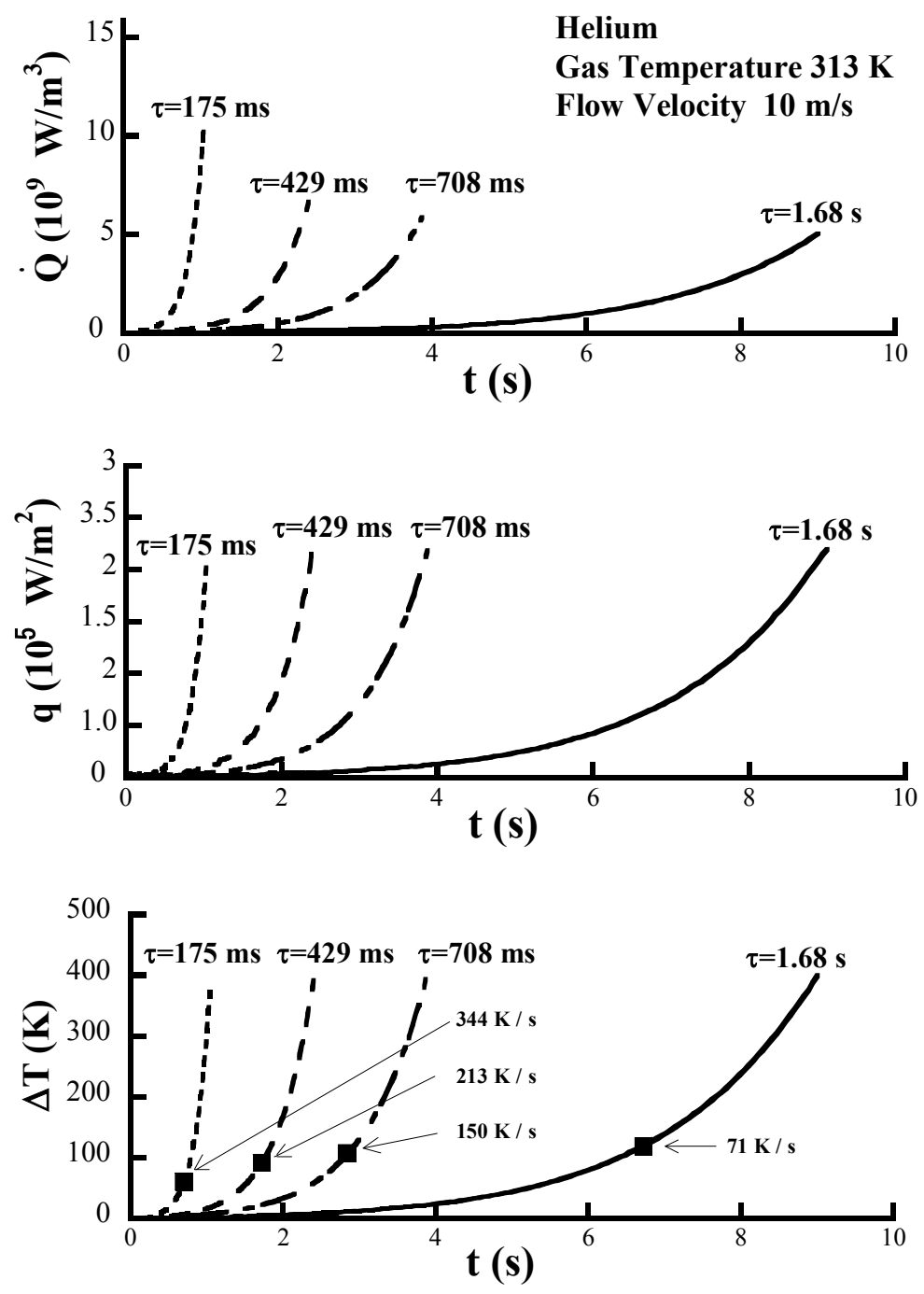

Fig.3 The relation of $\dot{\mathrm{Q}}, \mathrm{q}, \Delta \mathrm{T}$ with time at various periods for the gas temperature of $313 \mathrm{~K}$. 


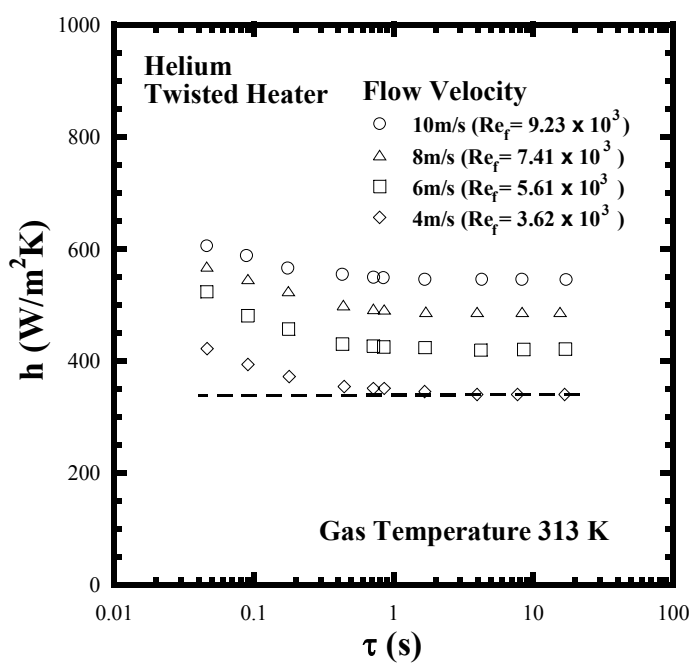

Fig.4 Heat transfer coefficients for helium gas at various periods and gas flow velocities.

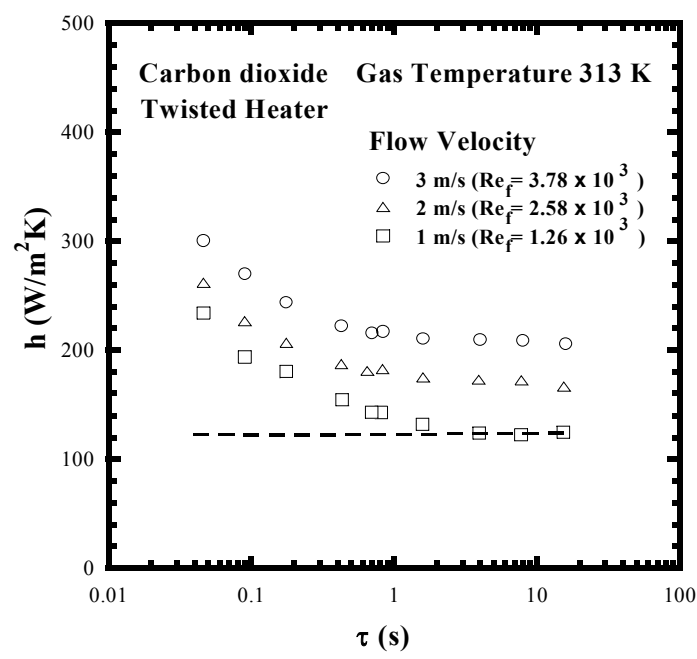

Fig.5 Heat transfer coefficients for carbon dioxide gas at various periods and velocities.

Figure 5 shows the typical experimental data of carbon dioxide gas at the temperature of $313 \mathrm{~K}$. These data show that they are divided into the quasi-steady-state heat transfer region and the transient heat transfer region on the boundary of around $1 \mathrm{~s}$ as well as the case of the helium gas.

\subsection{Comparison of the Experimental Data of Twisted Heater with Authors' Data of Plate Heater}

Figures 6(a) and 6(b) show the quasi-steady state and transient heat transfer coefficients compared with authors' experimental data of a plate heater ${ }^{(9),(11)}$. As shown in Fig. 6(a), the heat transfer coefficients are $13 \%$ higher than those with plate heater for helium gas at the flow velocity of $10 \mathrm{~m} / \mathrm{s}$ and gas temperature of $313 \mathrm{~K}$. And also, as shown in Fig. 6(b), the heat transfer coefficients are $28 \%$ higher than those with plate heater for carbon dioxide gas at the flow velocity of $3 \mathrm{~m} / \mathrm{s}$ and gas temperature of $313 \mathrm{~K}$. It is considered that the twisted heater shows an enhancement on the transient heat transfer. This is because the heat transfer coefficients are affected by the change in the flow due to swirling flow on the twisted heater. In general, the heat transfer enhancement on a twisted tape is attributed to following mechanisms ${ }^{(12)}$ : (1), swirl flow mixing, (2), increased flow velocity and flow length, (3), tape fin effects. In this case, it is considered that the partitioning and blockage of the flow cross section by the twisted heater arises higher flow 
velocities, the helically twisting fluid motion has an effectively longer flow path, and the secondary fluid motion is generated by the twisted heater.

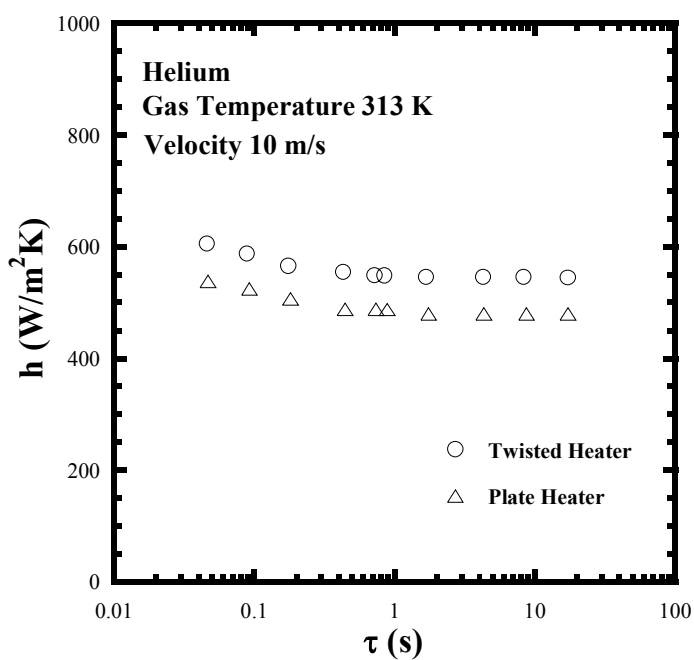

(a) helium gas

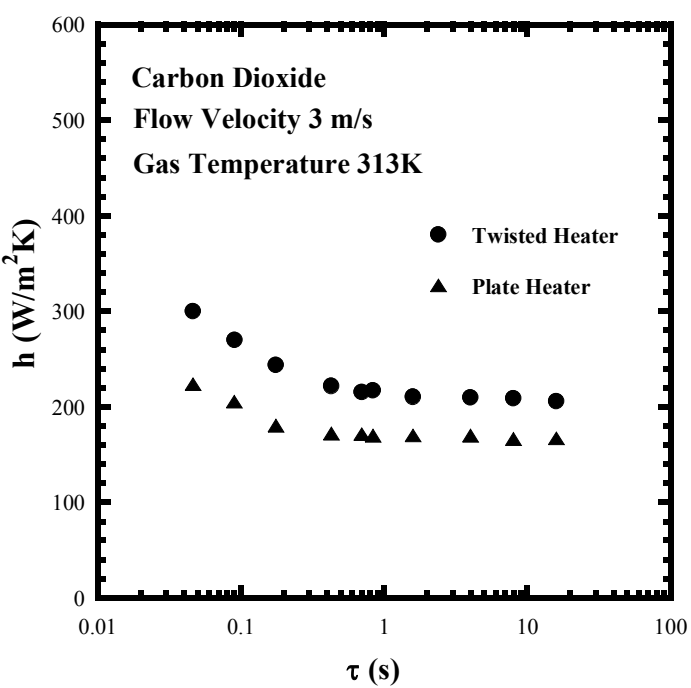

(b) carbon dioxide gas

Fig.6 Quasi-steady-state and transient heat transfer coefficients at various periods for the twisted heater and plate heater.

\subsection{Correlations for Quasi-Steady-State and Transient (Unsteady State) Heat Transfer} at Various Velocities and Periods

Figure 7 shows the relation between the Nusselt numbers and the Reynolds numbers for the periods ranging from $1.7 \mathrm{~s}$ to $16.5 \mathrm{~s}$ on the graph of $\mathrm{Nu}_{\mathrm{st}, \mathrm{f}} / \mathrm{Pr}_{\mathrm{f}}^{1 / 3}$ versus $\mathrm{Re}_{\mathrm{f}}$. As shown in the figure, for the periods longer than about $1 \mathrm{~s}$, the Nusselt numbers increase with flow velocity though they are not affected by the period. The Nusselt numbers can be correlated for helium gas by the following empirical equation.

$$
\mathrm{Nu}_{\text {st }, \mathrm{f}}=1.40 \operatorname{Re}_{\mathrm{f}}{ }^{0.5} \operatorname{Pr}_{\mathrm{f}}{ }^{1 / 3} \text { for twisted heater in helium }
$$

where, $\mathrm{Nu}_{\mathrm{st}, \mathrm{f}}=\mathrm{h}_{\mathrm{st}} \mathrm{L} / \lambda_{\mathrm{f}}, \mathrm{Re}_{\mathrm{f}}=\mathrm{UL} / \mathrm{v}_{\mathrm{f}}, \mathrm{Re}_{\mathrm{f}}$ ranged from $3.62 \times 10^{3}$ to $9.23 \times 10^{3}, \mathrm{~h}_{\mathrm{st}}\left(\mathrm{W} / \mathrm{m}^{2} \mathrm{~K}\right)$ is quasi-steady state heat transfer coefficient, $\mathrm{L}(\mathrm{m})$ is effective length of the heater, $\lambda_{\mathrm{f}}(\mathrm{W} / \mathrm{mK})$ is thermal conductivity, $\mathrm{U}(\mathrm{m} / \mathrm{s})$ is gas flow velocity, and $v_{\mathrm{f}}\left(\mathrm{m}^{2} / \mathrm{s}\right)$ is kinematic 
viscosity. The Prandtl number, $\mathrm{Pr}_{\mathrm{f}}$, is about 0.68 for helium gas in the range of this experiment. The values calculated by the following correlation (Eq. (5)) for the plate heater ${ }^{(10)}$ are shown in Fig. 7 for comparison. The heat transfer for twisted heater is $13 \%$ higher than the values obtained by Eq. (5).

$$
\mathrm{Nu}_{\mathrm{st}, \mathrm{f}}=1.24 \mathrm{Re}_{\mathrm{f}}^{0.5} \operatorname{Pr}_{\mathrm{f}}^{1 / 3} \text { for plate heater in helium }
$$

On the other hand, the following quasi-steady-state heat transfer correlation for carbon dioxide gas flowing over the twisted heater was similarly obtained as shown in Fig.8.

$$
\mathrm{Nu}_{\mathrm{st}, \mathrm{f}}=1.85 \operatorname{Re}_{\mathrm{f}}^{0.5} \operatorname{Pr}_{\mathrm{f}}^{1 / 3} \text { for twisted heater in carbon dioxide }
$$

where, $\mathrm{Re}_{\mathrm{f}}$ ranged from $1.26 \times 10^{4}$ to $3.78 \times 10^{4}$. The dashed line shown in Fig. 8 is the following correlation (Eq. (7)) obtained for a plate heater. Compared with the values of the plate heater, the heat transfer for twisted heater is $28 \%$ higher.

$$
\mathrm{Nu}_{\mathrm{st}, \mathrm{f}}=1.44 \mathrm{Re}_{\mathrm{f}}{ }^{0.5} \operatorname{Pr}_{\mathrm{f}}^{1 / 3} \text { for plate heater in carbon dioxide }
$$

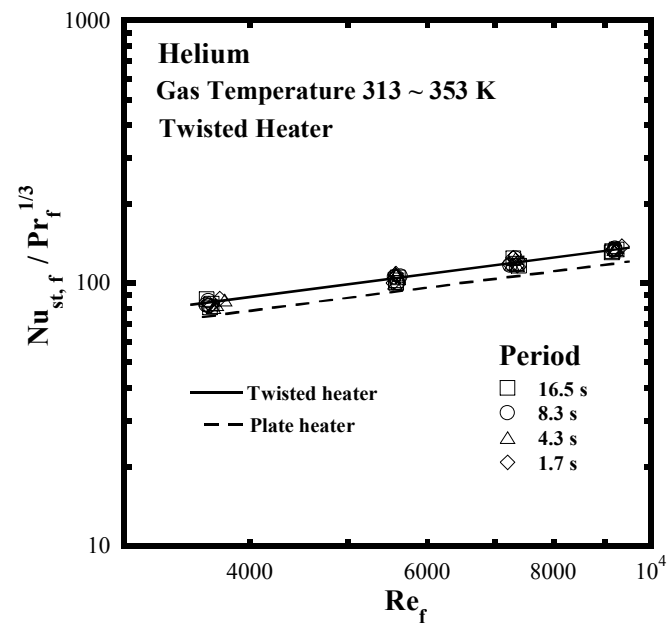

Fig.7 Quasi-steady-state heat transfer for helium gas at various periods.

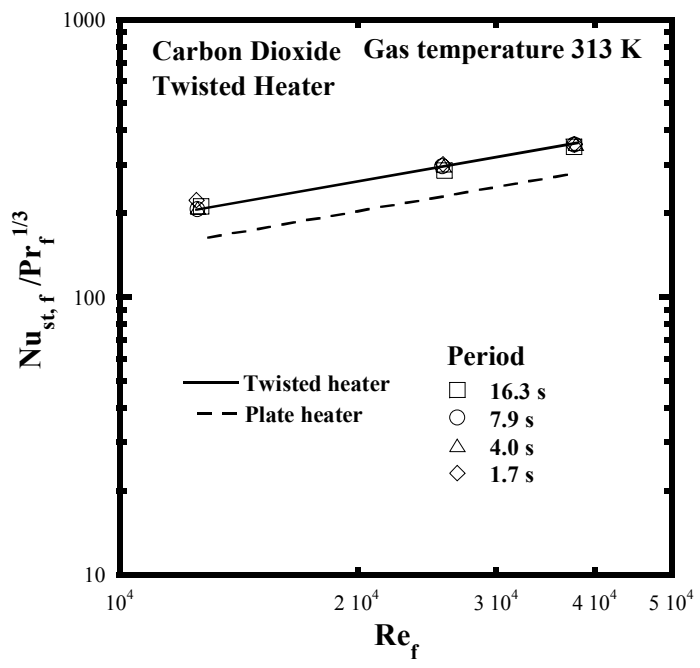

Fig.8 Quasi-steady-state heat transfer for carbon dioxide gas at various periods. 


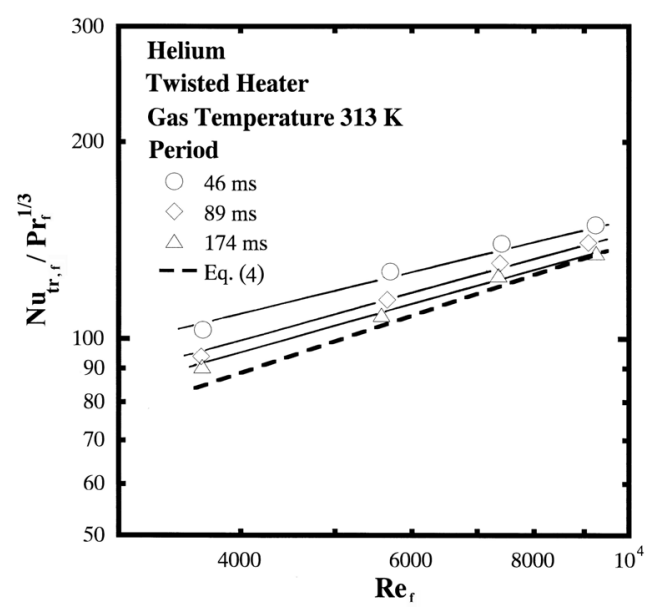

Fig.9 Transient heat transfer at various periods and Reynolds numbers under $313 \mathrm{~K}$.

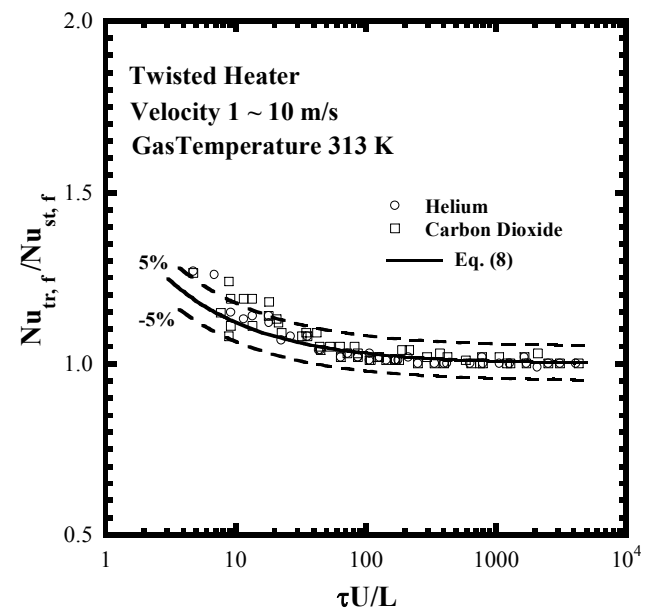

Fig.10 The relation of the ratios of $\mathrm{Nu}_{\mathrm{tr}, \mathrm{f}}$ to $\mathrm{Nu}_{\mathrm{st}, \mathrm{f}}$ with dimensionless period, $\tau \mathrm{U} / \mathrm{L}$.

Figure 9 shows the relation between the Nusselt number and the Reynolds number in the transient heat transfer of helium gas for the periods under about $1 \mathrm{~s}$. As shown in this figure, the Nusselt numbers are affected by both the period and the flow velocity. They approach asymptotic values in the quasi-steady-state heat transfer for the periods longer than about $1 \mathrm{~s}$ (dashed line, Eq.(4)). The effect of flow velocity becomes weak for shorter periods by decreasing the gradient of the data in the graph. The solid lines are the values by correlations for each period if they are correlated by the method of least squares.

As mentioned in the Introduction, Liu et al. ${ }^{(7)}$ carried out an experiment on the transient heat transfer of helium gas flowing across a horizontal cylinder at low Reynolds number region, and obtained an empirical correlation of the ratio of transient Nusselt number, $\mathrm{Nu}_{\mathrm{tr}, \mathrm{f}}$, to the quasi-steady-state $\mathrm{Nusselt}$ number, $\mathrm{Nu}_{\mathrm{st}, \mathrm{f}}$, using a dimensionless period of $\tau^{*}(\tau *=\tau \mathrm{U} / \mathrm{L})$. The present experimental data can be also correlated using the dimensionless period, $\tau \mathrm{U} / \mathrm{L}$, as shown in Fig.10. It can be seen from Fig.10, the ratios of $\mathrm{Nu}_{\mathrm{tr}, \mathrm{f}}$ to $\mathrm{Nu}_{\mathrm{st}, \mathrm{f}}$ decrease to unity as the nondimensional period increases. The transient heat transfer approaches quasi-steady-state one for the nondimensional period larger than about 100. The heat transfer shifts to the quasi-steady-state heat transfer for longer period and shifts to the transient heat transfer for shorter period at the same flow velocity. The transient heat transfer approaches the quasi-steady-state one for higher flow velocity at the same period. Following empirical correlation for the plate heater ${ }^{(10)}$ was shown as a solid line in Fig.10 for comparison. The experimental data for twisted heater at $\tau^{*}$ larger than 20 are 
within $\pm 5 \%$ of the values obtained by Eq. (8).

$$
\mathrm{Nu}_{\mathrm{tr}, \mathrm{f}}=\mathrm{Nu}_{\mathrm{st}, \mathrm{f}}\left\{1+0.48 \tau *^{-0.6}\right\}
$$

\section{Conclusions}

Forced convection transient heat transfer coefficients were measured for helium gas and carbon dioxide gas flowing over a twisted heater due to exponentially increasing heat input. Following results were obtained.

(1) Heat transfer coefficient approaches the quasi-steady-state one for the period over about $1 \mathrm{~s}$, and it becomes higher for the period shorter than about $1 \mathrm{~s}$.

(2) The geometric effect (twisted effect) of heater in this study shows a strong influence on the heat transfer coefficient. The heat transfer coefficients were $13 \sim 28 \%$ higher than authors' experimental data for the plate one.

(3) The correlations of quasi-steady-state heat transfer for the twisted heater were obtained based on the experimental data for helium gas and carbon dioxide gas.

\section{Acknowledgments}

This work was supported by the Japan Society for the Promotion of Science (JSPS) (Grant-in Aid for Scientific Research (C), KAKENHI, No.20560192), and Kansai Research Foundation for Technology Promotion (KRF) (Grant-in-Aid for scientific research 2007).

\section{References}

[1] U.S. DOE Nuclear Energy Research Advisory Committee and the Generation IV International Forum, "A Technology Roadmap for Generation IV Nuclear Energy Systems,” (2002), GIF-002-00, pp.54-58.

[2] Takamatsu, K., Nakagawa, S., Takeda, T., "Core Dynamics Analysis of Control Rod Withdrawal Test and Nuclear Characteristics in HTTR," Transaction of the Atomic Energy Society of Japan, Vol.5, No.2 (2006), pp.81-95.

[3] Siegel, R., "Heat Transfer for Laminar Flow in Ducts with Arbitrary Time Variation in Wall Temperature," Transaction of the ASME, Series E, 27-2(1960-6), pp.241-249.

[4] Soliman, M., Johnson, H.A., "Transient Heat Transfer for Forced Convection Flow over a Flat Plate of Appreciable Thermal Capacity and Containing an Exponential Time-Dependent Heat Source," Int., J. Heat Mass Transfer, Vol.11 (1968), pp.27-38.

[5] Kataoka, I., Serizawa, A. and Sakurai, A., “Transient Boiling Heat Transfer under Forced Convection,” Int. J. Heat Mass Transfer, Vol. 26-4 (1983), pp.583-595.

[6] Liu, Q.S., Fukuda, K., "Transient Heat Transfer for Forced Convection Flow of Helium Gas,” JSME International Journal, Series B, Vol.45-3 (2002), pp.559-564.

[7] Liu, Q.S., Fukuda, K., "Transient Heat Transfer from a Horizontal Cylinder in the Low-Reynolds-Number Flow of Various Gases," International Journal of Transport Phenomena, Vol.8 (2006a), pp.69-84.

[8] Liu, Q.S., Fukuda, K., Zheng, Z., "Theoretical and Experimental Studies on Transient Heat Transfer for Forced Convection Flow of Helium Gas over a Horizontal Cylinder," JSME International Journal, Series B, Vol. 49, No.2 (2006b), pp. 326-333.

[9] Liu, Q.S., Shibahara, M., and Fukuda, K., "Transient Forced Convection Heat Transfer for Helium Gas Flowing over a Horizontal Plate," Journal of Power and Energy Systems, Vol.1, No.1 (2007), pp.64-75.

[10] Liu, Q.S., Fukuda, K., and Shibahara, M., "Transient Heat Transfer for Helium Gas Flowing over a Horizontal Plate with Exponentially Increasing Heat Input," 
Proceedings of International Heat Transfer Conference (IHTC-13), Sydney, Australia, FCV-18 (2006d-8), pp. 1-10.

[11] Shibahara, M., Liu, Q.S., and Fukuda, K., "Transient Forced Convection Heat Transfer for Carbon Dioxide Flowing over a Horizontal Plate with Exponentially Increasing Heat Input," Proceedings of 2008 ASME International Mechanical Engineering Congress and Exposition, Boston, Massachusetts, IMECE2008-68603 (2008-11), pp.1-8.

[12] Manglik, R.M., Bergles, A.E., "Heat Transfer and Pressure Drop Correlations for Twisted - Tape Inserts in Isothermal Tubes: Part 1 - Laminar Flows," Journal of Heat Transfer, Vol. 115 (1993), pp.881-889. 